\title{
Mariana Bright
}

Lic. en Servicio Social (UNMdP)

Doctoranda en Trabajo Social (UNR)

\section{Miedo a los niños: una reflexión sobre la gestión de los riesgos a través de la intervención biopolítica sobre la niñez pobre}

\section{Resumen}

El hombre del Tercer Milenio ha sido condenado al miedo. Todo su mundo se ha tornado inestable, inseguro y plagado de amenazas que surgen de su propia vida cotidiana. Su aire, su agua, su alimento, sus semejantes son fuente de riesgos. El presente artículo se propone mostrar cómo la niñez es percibida hoy como amenazante y analizar aquellos dispositivos biopolíticos en juego para protegerse de ella.

Palabras claves

niñez $\cdot$ riesgo $\cdot$ biopolítica

\section{Abstract}

The man of the Third Millennium man has been sentenced to feel Fear. His world has become unstable, insecure and plagued with threats arising from their own daily life. His air, his water, his food, his neighbor are a source of risk. This article aims to show how Childhood is now perceived as threatening and analyze those devices biopolitics at stake to protect us of it.

\section{Keywords}

childhood $\cdot$ risk $\cdot$ biopolitics 


\section{Introducción}

Se habla de la situación actual de la Modernidad como una continuidad (Habermas, 1993) o una fractura (Lyotard, 1993). Se habla de un tiempo de padecer o corregir sus consecuencias (Lipovetsky, 2007). Sea cual fuere la fórmula que se utilice para intentar conceptualizar el tránsito histórico del hombre por este Tercer Milenio, la Modernidad propiamente dicha y todo el andamiaje que sostuvo la sociedad hasta el siglo XX, han dejado de existir.

Su advenimiento fundó una sociedad basada en la libertad, la igualdad, la ilusión de un futuro promisorio a ser construido desde el esfuerzo y la esperanza. A partir de una sencilla fórmula dada y según desde donde se partiera, se podía llegar a una meta precisa, ansiada y controlable.

El desvanecimiento de esas ilusiones y certezas ha sido un proceso lento, pero en el fragor de los tiempos generacionales y para aquellos nacidos a mediados del siglo XX, esas promesas son sólo un mito, una leyenda del pasado ancestral que los ancianos cuentan a su descendencia sin prueba alguna que le brinde consistencia. "Medidas por sus propios criterios, la mayor parte de los relatos se revelan fábulas" (Lyotard, 1993:9).

En el Tercer Milenio ya no hay promesas sino amenazas. El hombre solo y desnudo es arrojado a una tierra desconocida y hostil, librado a su suerte y signado, además, como culpable de su propio desmembramiento y exclusión (Beck, 1998; Castel, 2002; Bauman, 2004). Eros y Tánatos liberados se yerguen desde los desechos de un Yo débil e indefenso. Todo es Ello. El solitario hombre globalizado "está en riesgo" (Beck, 1998).

El concepto de riesgo que era utilizado en el siglo XVIII como un factor en cálculos probabilísticos para evaluar posibles pérdidas y ganancias ante inversiones, ha invadido el pensamiento y el discurso político del siglo XXI y su acepción sólo admite un sinónimo: peligro. El sentimiento de peligro tiende a socavar aún más las brechas que separan de por sí a los miembros de una sociedad. Ya religiosas, ya étnicas o principalmente económicas, como es el caso de Latinoamérica, las diferencias profundizan el sentimiento de peligro. No resulta dificultoso pensar que serán precisamente los grupos minoritarios aquellos que sufran las consecuencias al ser transformados en "portadores de riesgos". Su invisibilidad, propia de una sociedad individualista, se diluye y son vistos con toda la materialidad que la subjetiva percepción del riesgo les otorga. Y con su aparente visibilidad, se torna aún más profundo el estigma que determina su destino.

Si de invisibilidad hablamos, los niños han sido a través de la historia universal un mudo testigo de las transformaciones de una sociedad obstinada en ignorarlos, hasta que la incipiente modernidad volcó su atención en la necesidad de educarlos: "La familia y la escuela retiraron al niño de la sociedad de los adultos. La escuela encerró a una infancia antaño libre en un régimen disciplinario cada 
vez más estricto, lo que condujo en los siglos XVIII y XIX a la reclusión total del internado (...) Sin embargo, este rigor reflejaba otro sentimiento diferente de la antigua indiferencia: un afecto obsesivo que dominó a la sociedad a partir del siglo XVIII (...) cuando la familia acababa de reorganizarse en torno al niño y levantaba entre ella y la sociedad el muro de la vida privada" (Ariès, 1960).

La niñez latinoamericana cobra dimensión política a fines del 1800, pero como problemática "en la Argentina de fines del siglo XIX y principios del XX, se consolidó un modelo de intervención del Estado sobre los denominados niños en peligro. Vendedores ambulantes, mandaderos, lustrabotas, canillitas, hijos de inmigrantes, niños abandonados, jóvenes que cometían delitos, chicos que habitaban los inquilinatos, hijos de familias anarquistas, fueron sólo algunos de los niños y adolescentes que eran recluidos tras los muros de los asilos que se multiplicaban vertiginosamente en la ciudad de Buenos Aires" (Ponce, 2002).

Si duras han sido las consecuencias para los niños pobres ser definidos "en situación de riesgo", tantas más implicancias tiene en la vida y en los cuerpos de los niños, como veremos, ser considerados un riesgo en sí mismos.

\section{La soledad y la desesperanza}

Solo. El hombre del Tercer Milenio está condenado a la soledad y a cargar sobre sus espaldas la frustración de desconocer, no sólo su futuro sino su presente, ya que no le sirven las explicaciones del pasado. "Un enorme cúmulo de escritos redactados durante la segunda mitad del siglo XX presenta al público lector una y otra vez nuevas versiones de lo que en el fondo es el mismo personaje del ser humano aislado, en la forma de homo clausus o de yo carente de nosotros, y sumido en su soledad buscada o no. Y el amplio eco que encuentran tales escritos, la gran repercusión de su éxito, demuestra que la imagen del ser humano aislado y el sentimiento fundamental que presta fuerza a ésta no son un fenómeno aislado" (Elías, 1990:227-228).

Las viejas recetas, las antiguas convicciones, las acordadas normativas han perdido su poder para orientar la visión del mundo. Como si todas las señales aprendidas indicaran otra cosa o, peor aún, lo contrario. La vívida experiencia de los Ministerios de Orwell.

Solo y perdido, el hombre desconoce el punto de partida y de llegada. No obstante, es impelido a avanzar cada vez a mayor velocidad para no ser arrollado por los demás, inmersos en la misma carrera desquiciada. Un "juego de las sillas" donde hombres y mujeres están obligados a girar sin promesa de "completud" ni descanso (Bauman, 2004:39).

Gareteando, ciertos puertos brindan la fantasía efímera de una meta alcanzada en medio de la desesperanza permanente generada por la inexistencia de 
puertos reales donde recalar. Aun ante la reiterada frustración, se insiste en recurrir a la vieja cartografía e instrumental de viaje de la Modernidad, pero toda la tecnología resulta ineficaz para brindar datos seguros sobre dónde se encuentra la ansiada costa. El misticismo y lo mágico ocupan nuevamente el espacio de la esperanza. Asidos a la fe en lo intangible, lo invisible, lo inaudible, resulta menos peligroso tocar, ver y escuchar el entorno real. "La magia ayuda a aliviar, mediante pensamientos y actos cargados de fantasía, el carácter insoportable de una situación en la que, como niños pequeños, los seres humanos están expuestos a peligros misteriosos e incontrolables. Fórmulas y prácticas mágicas hacen que sea posible ocultar y desterrar de la conciencia los temores que produce esa situación, la total inseguridad y la vulnerabilidad que conlleva, el omnipresente horizonte de dolor y muerte" (Elías, 1990:96). Una extendida variedad de pócimas mágicas se ofrecen como bálsamo para aliviar las heridas provocadas por la soledad y la impotencia, anestesiando los sentidos y brindando la fugaz sensación de haber huido hacia la tierra prometida.

El hombre del Tercer Milenio está solo. Las redes que lo contenían y definían, aun las más próximas, se han debilitado hasta desdibujarse. La labilidad de las relaciones limita la posibilidad de acordar una terminología acabada para definir una trama de consanguinidades diluidas en el espacio y en el tiempo. Familia, pareja, padres, hijos, son conceptos que se multiplican en las percepciones subjetivas hasta convertirse en inteligibles. “¿Quién cree aún en la familia cuando los índices de divorcios no paran de aumentar, cuando los viejos son expulsados a los asilos, cuando los padres quieren permanecer 'jóvenes' y reclaman ayuda de los 'psi', cuando las parejas se vuelven 'libres', cuando el aborto, la contracepción, la esterilización son legalizadas?" (Lipovetsky, 2007:35).

En la necesidad de caminar en la oscuridad, la posibilidad de hacerlo junto a un otro es ambivalentemente vivenciada. A la tentadora oferta de mitigar la soledad, se contrapone la peligrosa tarea de construir un nosotros redefiniendo aquello que luego de un gran esfuerzo personal se evidenciaba finalmente sólido. "De ese modo, la tentación de enamorarse es avasallante y poderosa, pero también lo es la atracción que ejerce la huida” (Bauman, 2005:24). La emergencia del nosotros demanda flexibilizar fronteras, estrechar espacios, abandonar posiciones. Esto implica dejar en situación de suma vulnerabilidad la propia existencia. Ante esta posibilidad, que resulta altamente peligrosa, se intentan otras opciones que impliquen menor riesgo que nosotros, por ejemplo un yo + yo, o sea, una adición de individualidades, de soledades, que poco dista de la situación inicial tornándose escasamente satisfactoria, molesta y, por consiguiente, fácilmente desechable.

Lo virtual ha devenido en espacio seguro para intentar cubrir la imperiosa necesidad de un nosotros. No expone, no arriesga y permite jugar a un "como si” mágico y hasta patológico. Líneas y más líneas de máquinas enfrentadas 
a soledades temerosas; una junto a la otra; sin contacto, sin diálogo, pero en definitiva unidas por el sueño de construir un nosotros que les permita, aunque sea virtualmente, caminar en la oscuridad. Bajo la mascarada de un lazo global donde personas de lejanos pueblos son capaces de un entendimiento virtual, aquellos lazos que definen la subjetividad se encuentran totalmente desatados e incapaces de asir la comprensión intra e intergeneracional. "La gran diferenciación de la sociedad, que va de la mano de una gran diferenciación de las personas particulares, con una marcada individualización, conlleva una enorme multiplicidad y variabilidad de las relaciones personales. Una de sus variedades, no poco común, está marcada por el conflicto, antes mencionado, del yo carente de un nosotros: un anhelo de calor, de afirmación emocional de otras personas y a través de otras personas, ligado con la imposibilidad de ofrecer emociones espontáneas" (Elías, 1990:235).

Asolados vemos a nuestros jóvenes carentes de pasiones, escépticos y ayunos de compromisos. ¿Pasión por qué? ¿Creer en qué? ¿Comprometerse a qué? Ante la total pérdida del tiempo y el espacio como ejes de contención de la historia, viven en el plano unidimensional del "aquí y ahora", sin más que un presente continuo, indefinido, pero seguro. La seguridad del "aquí y ahora" funciona como un conjuro que los protege de la tenebrosa proyección hacia la "nada" que representa el futuro y que sus mayores no pueden ayudarles a imaginar.

Luego de trescientos años de lucha para alcanzar la libertad, al fin ha llegado el momento anhelado y somos libres para pensar, actuar, equivocarnos, perdernos, sucumbir a la soledad, al fracaso, a la autodestrucción, sin que exista más responsable que la propia voluntad.

Como se verá más adelante, tanto la "versión privatizada de la Modernidad" de Bauman como la perspectiva "biográfica" de Beck, refieren al proceso de individualización ${ }^{1}$ por el cual el hombre moderno fue instado a soltarse de las manos de sus comunes y desde su ensalzada libertad y potencial individual, usar ambas manos para tomar las oportunidades prometidas. El fracaso, entonces, no tiene otro responsable más que él. Todo estaba dado, sólo había que esforzarse un poco más para lograr sentarse en la "silla" del juego.

El desmoronamiento de la estructura moderna conlleva la pretensión de culpabilidad privada. Atribuida y asumida. Descontextualizada. En tanto el fracaso es particular, la estructura en declive se resiste a caer. Mientras la culpa individual invade los divanes, la colapsada Sociedad Moderna huye de los sociólogos.

Pero al "juego de la silla" se le suman nuevos indicadores que hacen que la crisis escape de la órbita personal y se postule como global. Todo aquel cuerpo normativo que brindaba contención y resguardo se ha resquebrajado hasta des-

1 Beck diferencia conceptualmente el término "individualización”, de aquel acuñado a comienzos del siglo XX por Georg Simmel, Emile Durkheim y Max Weber. (BECK, 1998a:35). 
plomarse sobre la propia Modernidad. A la soledad se le suman la inseguridad y el miedo.

\section{La inseguridad y el miedo}

Están cuestionadas las propias coordenadas que orientaban a la sociedad moderna ofreciendo seguridad, control y brindando fundamento al estilo de vida burgués, sus instituciones y organización reglamentaria. La autoridad en todas las esferas y ámbitos (desde el familiar hasta el global) ha sido interpelada, sentada en el banquillo de los acusados e impelida a dar explicaciones sobre sus decisiones, actos y omisiones. Las reglas son claras: no existen reglas. La Ley ha sido reemplazada por pequeños acuerdos caseros, inestables e incapaces de brindar protección. "Si las tropas de la regulación normativa abandonan el campo de batalla de la vida, sólo quedan la duda y el miedo" (Bauman, 2004:26).

El miedo individual generado por la inseguridad y la soledad, se ha redistribuido y potenciado a través de la información, que invade y penetra en los sentidos, principalmente de manera inconsciente. El robo a un vecino del barrio y un coche bomba en Irak, son vivenciados con la misma intensidad y sensación de desprotección. Los misiles de la información apuntan directamente al corazón del hombre.

El temor ha usurpado todo espacio de independencia. Lo atestigua la reproducción de las fobias, los ataques de pánico y su máximo exponente, el panic room, cuya construcción se ha convertido en una empresa sumamente rentable para algunos, garantizando un espacio de seguridad al interior del propio hogar, otrora fuente de protección per se. El sol, el mar, el frío y el calor; el futuro de los hijos; los propios hijos; las personas cercanas, los extraños; las pérdidas, los encuentros...todo es motivo de un temor intenso e indeterminado que inmoviliza la acción y el pensamiento.

Tres son los caminos posibles para conjurar los miedos: la locura, la violencia y el enfrentamiento crítico. La locura evidencia ser una salida posible en la convivencia forzada con los miedos del Nuevo Tiempo, llamando locura a la conducta resultante de la respuesta coherente con los estímulos externos. A cada amenaza le corresponde una acción preventiva. A cada temor le corresponde una acción defensiva. $\mathrm{O}$, en su defecto, la posibilidad de protegerse indistintamente de todos los potenciales temores, emparedándose a fin de no ser acorralado por éstos.

Atribuida de manera exclusiva a los "bárbaros modernos": inadaptados, crueles, carentes de capacidad de reflexión e introspección, lo cual es un sofisma utilizado para fundamentar la represión de ciertos grupos, la violencia no es más que una respuesta al miedo. Instintiva e inespecífica como la propia amenaza, la 
violencia brinda la frágil sensación de "tener el control". Ante la pérdida de la Ley como espacio de contención social y familiar, las normas se fundan individualmente a sangre y fuego. La "natural" supervivencia del más fuerte. Desarmados y desnudos, enfrentados a las consecuencias de sus actos más salvajes, sólo queda el miedo.

Pero ni la retirada ni el ataque son estrategias válidas en la guerra contra los miedos. De hecho, la sola declaración de guerra ya implica una derrota. La posibilidad de enfrentar los temores implica pararse frente a ellos, cara a cara y reconocerlos, fragmentarlos, rastrear sus fuentes, socavar sus propias entrañas, hasta lograr percibirlos como obstáculos pasibles de ser desafiados, aun con las escasas armas disponibles.

\section{De la individualización a la soledad: un fenómeno social}

Surgido en el seno de la propia Modernidad, de sus postulados y como uno de sus efectos colaterales, el proceso de individualización desmembró la sociedad, desgajando las organizaciones y desprendiendo a las personas de sus espacios tradicionales, de sus pertenencias comunitarias y familiares. De compromisos que se encontraran fuera de la esfera exclusivamente personal, principalmente de aquellos que pudieran entorpecer los proyectos individuales.

Hombres y mujeres fueron señalados como hacedores de su destino individual, fuera de aquellos grupos de referencia que los contenían y definían como miembros. Los principales golpes fueron asestados a las formas tradicionales de familia y las organizaciones sociales de primer orden. Luego, como efecto dominó, fueron golpeados unos tras otros todos los espacios de pertenencia hasta desintegrar la propia estructura de clases; hoy en día y globalización mediante, estamos siendo testigos de la pérdida de la propia nacionalidad. El hombre ha pasado a ser un solitario habitante del mundo. "En este sentido, la individualización tiende a eliminar las bases que tiene en el mundo de la vida un pensamiento que emplea categorías tradicionales de las sociedades de grupos grandes (clases sociales, estamentos o capas)" (Beck, 1998:96).

El mundo del trabajo, históricamente considerado un nexo sociocultural de inscripción a los diversos sectores sociales, ha sido atomizado e hiperespecializado por la Modernidad, dañando la adscripción de los hombres a dichos sectores: "...las regulaciones colectivas se debilitan, segmentos de la sociedad devienen débiles, debilitados y un número creciente de individuos se encuentra desgajado de sus pertenencias colectivas. $Y$ me parece que esto es una dimensión importante de los procesos de individualización del trabajo de la sociedad moderna" (Castel, 2001:21). El derrumbamiento de las economías a partir de los 
años '70, con la consecuente desocupación masiva, le dio el golpe mortal a los "grupos de pertenencia" y el hombre quedó definitivamente solo.

"Para analizar lo social, hay que recurrir cada vez más a la historia individual antes que a la sociología" (Rosanvallon, 1995:192). La premisa del autor de psicologizar la individualización es compartida por muchos, principalmente por aquellos a quienes les compete la toma de decisiones respecto a la aplicación de políticas sociales destinadas a paliar sus consecuencias. Si la responsabilidad y el impacto son individuales, el tenor de la asistencia carece de real compromiso, dado que se asienta en el propio individuo y en su potencial deseo o no de revertir su situación. Así, vemos reiterarse propuestas asistenciales que desdeñan alternadamente o al "pescado" o al "curso de pesca", revictimizando una y otra vez al individuo, ora porque no sabe cocinar pescado, ora por no tener constancia en la tarea de la pesca. Pero centrando al propio individuo como mentor de una situación de la que, por acostumbramiento o comodidad, no desea salir.

¿Puede ser analizada la realidad social, aún envenenada por la soledad humana, desde una perspectiva netamente "biográfica"? La emergencia de la individualización y sus tribulaciones es un fenómeno masivo y no puede ser analizado sino desde una perspectiva sociológica. La individualización es un proceso social y sus consecuencias han generado problemáticas sociales. La perspectiva psico-biográfica sesga el análisis y lo torna inacabado y estéril para la acción.

"No hablo de psicología cuando digo 'individuos', sino que el hecho de poder vivir positiva o negativamente como individuo es una construcción social (...) Es decir, que si estas nuevas individualidades son analizadas, esto no significa que se trate de casos singulares. Es también un fenómeno de masas, pero que toma siempre la configuración de un destino particular. De ahí la tentación a veces de psicologizar esta situación, tentación a la que creo que hay que resistirse" (Castel, 2001:22).

\section{Individualización, estigma e identidad}

Ulrich Beck critica a quienes consideran que el proceso de individualización propio de la Modernidad conlleva al aislamiento y a la soledad, señalando que dicho proceso es distinto según el desarrollo alcanzado por las distintas sociedades (Beck, 1998:129)2.

2 Aclara el autor, que dicho proceso implica tanto desintegración de modelos tradicionales, como su posterior sustitución por nuevos modelos y conformaciones. Por ello lejos de destruirse, "lo social" adquiere nuevas posibilidades de construcción de ligazones y obligaciones sociales. Pero también distingue diferentes alcances del proceso de individualización dependiendo del nivel de desarrollo alcanzado por los Estados. En los países del denominado Tercer Mundo el impacto de dicho proceso ha cobrado una dimensión totalmente distinta a la planteada; lo que Beck denomina: "La individualización de la pobreza". 
En los últimos cincuenta años de la Argentina hemos sido testigos de la inmersión en la más profunda globalización, pero sólo de ciertos sectores; de la sujeción a los mandatos contradictorios de una Modernidad en declive; del achicamiento y posterior desaparición del Estado providencia; de la expulsión masiva de partes de la sociedad de todo anclaje y nicho de pertenencia; de sucesivas crisis económicas y políticas; del desplazamiento de los Derechos de los Ciudadanos a la declamación vacía por los Derechos Humanos.

A las inestabilidades habituales de los países del Tercer Mundo, debatiéndose por emerger hacia una cuasi modernidad por debajo del pie de los Todopoderosos, se le ha sumado la fractura de la propia Modernidad. La disolución de la Sociedad Moderna antes de su propio establecimiento pleno, la incompletud del proceso de transformación, ha deparado un panorama distinto al del mundo desarrollado.

El proceso de individualización se ha concretado también de manera incompleta en nuestro hemisferio, presentando sólo su primera fase: desintegración. Los nichos de adscripción de lo social se diluyeron, quedando solamente sus formas fantasmagóricas, sin generarse nuevos espacios de inclusión. ¿Este inacabado planteamiento de la Modernidad y su crisis, es una ventaja o una desventaja para que nuestros pueblos se encaminen en este Nuevo Tiempo? ¿Habrá entre los desechos del naufragio fragmentos a los que asirse?

No existen demasiadas respuestas que superen la mera expresión de deseo; pero en el intento irreverente por construir, bautizar y normatizar este Nuevo Tiempo que nos atraviesa, la posibilidad de completar el proceso de individualización con la sustitución por nuevas formas de lo social que permitan la reinclusión de los solitarios y de los expulsados como partes de, miembros de, se constituye en un imperativo para la superación de la soledad y el miedo.

No obstante, la posibilidad de una biografía elegida, de reinventar la identidad, las relaciones y la propia participación en la vida política, ha sido negada en Latinoamérica para un creciente número de personas que se encuentran por fuera del sistema social. Por ello, contingentes de expulsados ${ }^{3}$ se ven privados de toda posibilidad de reinvención, de construcción, de inserción en nuevos nichos de identidad, siendo condenados al ostracismo.

Tal como señala Mary Douglas, por una parte el estigma como profecía autocumplida, genera que los discursos prejuiciosos se justifiquen y reproduzcan. Pero, asimismo, el estigma visibiliza a las minorías. Esta ilusión de visibilidad repentina ha producido que la endíadis "pibes chorros" se convirtiera en el refugio identitario de muchos niños pobres en busca de reconocimiento. De este modo, la tríada estigma/visibilidad/riesgo ha configurado la excusa perfecta para

3 Véase Duschatzky \& Corea (2002) Expulsión no refiere a la sola imposibilidad de integración, sino al resultado de una operación social, una producción, un modo de construcción de lo social. 
brindarle materialidad a la amenaza, a pesar de la debilidad de sus conexiones causales.

Como en una obra teatral, recae en el escenario biográfico de los niños pobres una poderosa lumbre que los torna visibles, en el preciso momento en que tienen un arma en sus manos. Luego, la luz se apaga y nuevamente la niñez hace mutis por el foro para no volver a aparecer nunca más ante los ojos del público. Ese público, la Sociedad de Riesgo, imbuida en sus soliloquios y acechada por los temores de la inseguridad, ha convertido ese instante de luz sobre la vida de los niños, en una de sus pesadillas y pide a cualquier costo que la escena no vuelva a repetirse.

"La escenificación de la situación de los suburbios pobres como abscesos donde está fijada la inseguridad, a la cual colaboran el poder político, los medios y una amplia parte de la opinión pública, es de alguna manera el retorno de las clases peligrosas, es decir, la cristalización en grupos particulares, situados en los márgenes, de todas las amenazas que entraña en sí una sociedad" (Castel, 2004:70).

La "sobrecogedora simplificación", al decir de Castel, del discurso que postula la responsabilidad de ciertas minorías sociales de la problemática global de la inseguridad, ha implicado todo un reordenamiento jurídico y administrativo dirigido a "condenar" las consecuencias de una cuestión social cuyas causas son prolijamente ignoradas.

Se produce entonces una solución judicial de la inseguridad civil, que encubre la necesidad de una solución política de la inseguridad social. Esta especie de paronomasia, este juego de palabras, define la estrategia con la que las instituciones del poder político, heridas de la incredulidad de los ciudadanos, reorganiza su respuesta protegiendo a la sociedad, identificando y castigando a los culpables de sus males. Víctimas y victimarios pasan a ser dos identidades social, mediática y políticamente determinadas y legitimadas. Se reestructuran entonces, como veremos más adelante, los dispositivos necesarios para que las amenazantes clases peligrosas sean apartadas de una sociedad de la que jamás fueron parte.

\section{El derecho de los invisibles}

Desde los vientres maternos, los niños como mudo y difuso telón de fondo de la Historia de la Humanidad, fueron y son atravesados permanentemente por las decisiones políticas de cada época y de cada sociedad.

Dice Lloyd De Mause: "La historia de la infancia es una pesadilla de la que hemos empezado a despertar hace muy poco. Cuanto más se retrocede en el pasado, más bajo es el nivel de la puericultura y más expuestos están los niños a 
la muerte violenta, al abandono, los golpes, al temor y los abusos sexuales" (De Mause,1991:15 apud Alzate Piedrahita, 2002).

Ya sean tomados como hombres en miniatura, hombres débiles, hombres incompletos e insensatos para la vida política, económica, guerrera. Cohabitando junto a sus mayores o encerrados "en una especie de cuarentena antes de dejarlos sueltos en el mundo", al decir de Ariès, los niños han transitado la historia de los hombres, en un doble juego de invisibilidad/visibilidad, basada en las cambiantes percepciones de la sociedad en función de las condiciones sociopolíticas imperantes.

Este cambio en la concepción de la niñez no ha sido un proceso evolutivo donde a través del paso de los siglos se ha ido reposicionando a lugares de mayor visibilidad y mejores condiciones de vida; se trata de una lenta modificación en el imaginario social, ora favorable, ora desfavorable para los niños y en todos los casos determinante del curso de su vida, de su suerte y de su muerte.

El Tercer Milenio y su Modernidad de Riesgo ha deparado para la niñez y en especial para la infancia pobre, nuevas concepciones e imágenes. Envueltos en el aura del temor y la inseguridad permanentes y ante el fracaso de la escuela como el dispositivo maestro de control desde hace casi diez siglos, los niños han pasado a adquirir una borrosa, casi fantasmagórica y amenazante, presencia. Los hombres pequeños de la Edad Media, ya no son considerados débiles para la guerra. Por el contrario, se perciben como una seria amenaza para la paz social.

Desde mediados del siglo XX, los niños son preconizados como sujetos de derecho, brindándoles una aparente visibilidad que permite su reconocimiento, al tiempo que se reordenan los dispositivos de control que los confinarán nuevamente a las sombras de la vida social.

Bauman califica como "fatídica retirada" al desplazamiento que el discurso político hiciera al dejar de postular como un objetivo común la construcción de una sociedad justa, para comenzar a hablar del derecho individual de los hombres a ser respetados en sus diferencias y a construir su propio destino. Si los derechos humanos no se fundan en la adscripción de hombres, mujeres y niños como miembros de una sociedad, dichos derechos se vacían de contenido y se transforman en una declamación histriónica. “... los pretendidos derechos sagrados e inalienables del hombre aparecen desprovistos de cualquier tutela y de cualquier realidad desde el momento mismo en que deja de ser posible configurarlos como derechos de los ciudadanos de un Estado" (Agamben, 1998:161).

El paradigma que ha pretendido instalar la Declaración Internacional de los Derechos del Niño, enmarcada en un contexto de derrumbamiento de las instituciones propias de la Modernidad, de individualización, de profunda inequidad, de invisibilidad y miedo, parece tornarse un vano esfuerzo declamatorio. Pero en 
manos de un poder que insiste en ignorar minorías, controlarlas, generar nuevos dispositivos para moldear la sociedad, la declamación se vuelve peligrosa.

Ese mismo Derecho por el cual los niños han pasado a ser Sujetos, vuelve en sus prácticas a cosificarlos en nombre de su protección. Los encierra para cuidarlos y una vez más los aleja del escenario político. Desde esta línea de análisis surge el siguiente cuestionamiento: ¿la aparente paradoja del Derecho de los Invisibles, no evidenciaría ser más bien un artilugio político ante la necesidad, sesgada por el temor, de nombrar para controlar?

\section{Gestión biopolítica de la niñez}

Convertida en problemática, "la niñez" tuvo en la Argentina de fines del siglo XIX un destino de padecimientos. La intervención del Estado se dirigió a los llamados "niños en riesgo" que proliferaban en las calles de una Buenos Aires que comenzaba a trazar los límites precisos de la más cruenta inequidad. Con la sanción de la Ley de Patronato, la respuesta estatal a la "problemática" fue el fortalecimiento y consolidación del asilo como dispositivo de control de esa niñez, fruto de inmigrantes pobres que habían llegado a la tierra prometida. La ecuación era sencilla: origen popular e inmigrante = delincuente. Con lo cual era menester que el Estado frenara esta tendencia, educando bajo preceptos morales y nacionales a estos niños que eran socialmente huérfanos. "La nueva sensibilidad por la infancia que se fue abriendo paso en Buenos Aires hacia fines del siglo XIX transformó a la niñez en objeto de variadas reflexiones y preocupaciones tanto desde el Estado como de la sociedad civil. Para esos años ya estaban perfilados dos discursos que reconocían la existencia de una niñez fragmentada. Por un lado, la figura del hijo-alumno, hijo de una familia nuclear y alumno de una escuela pública. Por otro, la figura del menor, asociada a los niños huérfanos, abandonados o trabajadores, todos ellos necesitados de asistencia en instituciones especiales porque el sistema educativo no lograba incorporarlos o retenerlos" (Armus, 2007:87).

Ruth Kochen (1993) plantea que aquellas ideas de inferioridad de la raza americana que justificaron en la América colonial el sojuzgamiento de los pueblos originarios, fueron el basamento para considerar la incapacidad de los inmigrantes europeos para formar familias estables capaces de educar moralmente a sus hijos. Los mecanismos tradicionales de control se encontraban superados, por lo cual era necesario "proteger" y "corregir" a los menores. "Si hacemos un poco de historia vemos cómo la tutela fue usada para someter y explotar a los 'inferiores': negros esclavos, inmigrantes, menores. Los racistas del siglo pasado y de principios del actual sostenían que la esclavitud era una institución de protección y que los negros y mulatos debían ser tutelados o protegidos, salvo en 
el penal por considerarlos peligrosos y salvajes. La antropología británica de la época decía que “los salvajes eran parecidos a los niños”' (Kochen, 1993:159).

Luego de un siglo y con la suscripción de nuestro país a la Convención Internacional de los Derechos del Niño, la adecuación normativa de la Ley de la Niñez a la perspectiva de derechos, fue un lento y tortuoso proceso. La crisis económica y social atravesó el país desde 1998 con epicentro en los levantamientos del 2001; la creciente exclusión y pauperización de nuevos sectores de la sociedad, generó un contexto de violencia e inseguridad que puso en jaque la gobernabilidad del país. Las voces de la opinión pública y de muchos funcionarios de gobierno, solicitaban mano dura como la única forma de volver a restaurar la paz y el orden social. La judicialización de la pobreza continuaría cumpliendo una función preventiva y hasta correctora del quebrado sistema social. El erario público no estaba en condiciones de afrontar los gastos que implicaba modificar la estructura vigente en materia minoril. Sólo se hacía necesario invertir en la construcción de nuevos institutos de privación de la libertad, que de hecho se estaban levantando en el territorio nacional al tiempo que, paradójicamente, se discutía la cristalización de la perspectiva de derechos en el campo normativo de la niñez.

Diecisiete años de debates se materializaron en las normativas vigentes de Promoción y Protección de los Derechos de Niños, Niñas y Adolescentes y del Sistema Penal Juvenil, brindando tratamiento diferencial a los niños con derechos vulnerados (en riesgo) y los niños en conflicto con la Ley Penal (de riesgo).

Cambiaron algunos de los actores; se desarrolló un sinnúmero de floridos eufemismos; se modificaron y complejizaron los circuitos burocráticos, pero las concepciones y las prácticas que éstas implican han permanecido prácticamente inmutables. Los hijos pobres de los pobres continúan siendo sometidos a las decisiones de un poder político que se niega a mirarlos a los ojos, mientras que el tema de la inseguridad social continúa sin ser abordado y, por lo tanto, la Protección de los Derechos se confirma como una deuda pendiente. "Pareciera que esta figura jurídica queda reservada únicamente a los niños de sectores humildes. ¿Qué pasa cuando un chico de clase media o alta comete un delito o se lo considera en riesgo? Por lo general no son 'clientes' de institutos, sino que son derivados a psicólogos, adquiriendo la categoría de "pacientes"' (Kochen, 1993:158).

En respuesta a las demandas sobre inseguridad civil, la temática de los niños en conflicto con la Ley Penal se ha tornado valle fértil para vislumbrar el retorno de las clases peligrosas. Se suceden los debates polarizados de políticos, científicos, opinólogos y víctimas en pos de determinar la edad en que los "pibes chorros" pueden ser considerados imputables, las características diferenciales de los dispositivos abiertos y cerrados de protección, la finalidad educativa y sancionadora de la pena, etc. 
En el marco de este discurso hegemónico con la reducción de la Niñez pobre a la temática del riesgo, se reiteran las expresiones de solaz cada vez que un "pibe chorro" es abatido: "iUno menos!". Esto nos remite directamente a aquellas reflexiones agambenianas sobre los conceptos diferenciales de los griegos para definir a la vida (zoé simple vida natural y bios manera de vivir la vida propio de un individuo). Los "pibes chorros" son la versión de aquellas vidas carentes de todo valor social; nuda vida, una vida desnuda (zoé) que no merece ser vivida, excluida del ámbito de las polis, pero que debe ser venerada y protegida por el sólo hecho de ser un bien en sí misma. "...ello dice relación con el imperativo moral cuasi teológico de defender la infancia a toda costa, donde la convención de los Derechos de los Niños aparece como los diez mandamientos o más bien como el código de Hamurabi, y su jurisdicción llega a mutilarla con el aparato psicosociojurídico empleado aporéticamente con el fin de preservarla, de defender sus derechos" (Hinrichsen, 2009:146). Estos aparatos psicosociojurídicos de los que habla el autor, nos remiten a aquellos foucaultianos de acceso de la zoé a las agendas y cálculos del poder estatal, transformándose la política en biopolítica. "La vieja potencia de la muerte, en la cual se simbolizaba el poder soberano, se halla ahora cuidadosamente recubierta por la administración de los cuerpos y la gestión calculadora de la vida" (Foucault, 1998:170).

Tanto el Paradigma de la Protección como el Sistema de Justicia Especializada se constituyen, entonces, en una continuidad en el tratamiento biopolítico de la Niñez, a la luz de los (sólo nominalmente) nuevos dispositivos de control y de disciplinamiento de los cuerpos infantiles, atendiendo a la premisa de: "Considerar las prácticas penales menos como una consecuencia de las teorías jurídicas que como un capítulo de la anatomía política" (Foucault, 2002:35).

La niñez pobre ha sido y es objeto de ese biopoder, capaz de determinar apelando a fundamentos científicos el momento en que se inicia su vida, la permanencia o no en su medio familiar, la edad cronológica y madurez psicológica necesarias para que sea considerado responsable de sus actos y la necesidad de recluirlo para, paradójicamente, proteger su futuro y el de la sociedad toda.

\section{Referencias bibliográficas}

AGAMBEN, G. Homo Sacer: el poder soberano y la nuda vida. Valencia. Editorial Pretextos Patena, 1998.

ALZATE PIEDRAHITA, M. “El 'descubrimiento' de la infancia: historia de un sentimiento”, en: Revista de las Ciencias Humanas, Colombia, 2002, [en línea 20/02/10] Disponible en: http://www.utp.edu.co/ chumanas/revistas/revistas/rev30/index.htm 
ARMUS, D. La ciudad impura. Salud, tuberculosis y cultura en Buenos Aires, 1870-1950. Buenos Aires, Edhasa, 2007.

ARIÈS, P. "El niño y la vida familiar en el Antiguo Régimen" [en línea 20/02/10] Disponible en: www.iin.oea.org/iin/cad/sim/pdf/mod1/Texto\%2015.pdf

CASTEL, R. La inseguridad social ¿Qué es estar protegido? Buenos Aires, Manantial, 2004.

BAUMAN, Z. Modernidad líquida. Buenos Aires, Fondo de Cultura Económica, 2004.

BECK, U. La sociedad de riesgo. Hacia una nueva modernidad. Buenos Aires, Paidós, 1998.

DOUGLAS, M. "Risk as forensic resource. From "chance" to "danger"”, en: Journal of the American Academy of Arts and Sciences. Vol. 119, № 4, 11 - 16. Cambridge, Daedalus, 1990.

DUSCHATZKY, S., COREA, C. Chicos en banda: los caminos de la subjetividad en el declive de las instituciones. Buenos Aires, Paidós, 2002.

ELIAS, N. La sociedad de los individuos. Ensayos. Barcelona, Ediciones Península, 1990.

FOUCAULT, M. Historia de la sexualidad I. La voluntad de saber. México DF, 1998, [en línea: 20/02/10] Disponible en: www.uruguaypiensa.org.uy/imgnoticias/681.pdf

FOUCAULT, M. Vigilar y castigar: nacimiento de la prisión. Buenos Aires, Siglo XXI Editores Argentina, 2002.

HABERMAS, J. El discurso filosófico de la modernidad. Madrid, Taurus, 1993.

HINSRICHSEN, F. "SENAME ¿Protección o punición? Comentarios de su acción biopolítica y disciplinaria”, en: SUMMA Psicológica UTS Vol. 6 Nº 2 págs. 143 -154. México DF, 2009 .

KOCHEN, R. "Menores en situación de riesgo en la Argentina", en: Cuadernos de trabajo social. Universidad Complutense. № 6, págs. 155 - 165. Madrid, 1993.

LIPOVETSKY, G. La era del vacío: ensayos sobre el individualismo contemporáneo. Barcelona, Anagrama, 2007.

LYOTARD, J. La condición posmoderna. Buenos Aires, Editorial Planeta, 1993.

PONCE, G. Los hijos invisibles del Estado: consecuencias en la vida adulta de la tutela estatal. Instituto Interamericano del Niño. Buenos Aires, 2002 [en línea: 20/02/10] Disponible en: http://www.iin.oea.org/Revista\%20Bibliografica_239/Monografia_Los_hijos_ invisibles_del_Estado.htm\#_ftnref1 